\section{ПРОБЛЕМЫ РЕГУЛИРОВАНИЯ И ПРАВОПРИМЕНИТЕЛЬНАЯ ПРАКТИКА ПРИМЕНЕНИЯ МЕР ПРИНУЖДЕНИЯ В ВИДЕ ИЗОЛЯЦИИ И ПРИНУДИТЕЛЬНОЙ ГОСПИТАЛИЗАЦИИ ПО ЭПИДЕМИОЛОГИЧЕСКИМ ОСНОВАНИЯМ}

Аннотация. В статье рассматривается возможность применения принудительной госпитализации и изоляции к лицам, зараженным коронавиром, и к лицам, контактировавшим с больным (больными). Автором выделяются такие механизмы принуждения, как принудительные меры и обязательные меры. Кроме того, автор проводит различие между понятиями «госпитализация» и «изоляция», анализирует субъектный состав соответствующих правоотношений. Научные и теоретические положения статьи иллюстрируются автором на примере российского законодательства (кодексов и других федеральных законов, подзаконных актов Министерства здравоохранения РФ и Роспотребнадзора, относящихся как к материальному праву, так и к процессуальному праву), а также практики, сложившейся или только складывающейся в отечественных судах. B статье описываются существующие проблемы регулирования, в частности дублирующее регулирование, и предлагаются способы их решения, в частности межведомственное взаимодействие Минздрава России и Роспотребнадзора в вопросе определения оснований для госпитализации и изоляции.

Ключевые слова: коронавирусная инфекция, COVID-19, госпитализация, изоляция, административное принуждение, административное судопроизводство, меры процессуального принуждения, Кодекс административного судопроизводства РФ, санитарно-эпидемиологическое законодательство.

DOI: 10.17803/2311-5998.2021.82.6.109-115

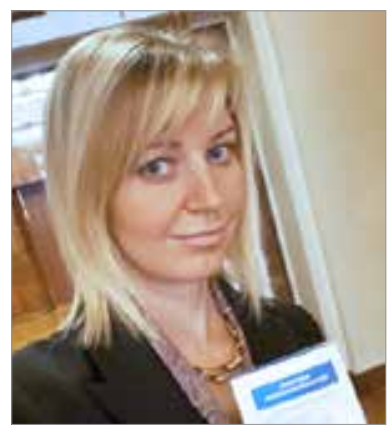

Ольга Владимировна СОКОЛОВА,

доцент кафедры административного и финансового права МГИМО (У) МИД России, кандидат юридических наук sokolova.olga.mgimo@ inbox.ru

117454, Россия, г. Москва, просп. Вернадского, д. 76 


\title{
O. V. SOKOLOVA,
}

Associate Professor, Department of Administrative and Financial Law of the MGIMO University, Cand. Sci. (Law) sokolova.olga.mgimo@inbox.ru 76, pr. Vernadsky, Moscow, Russia, 117454

\section{REGULATORY ISSUES AND LAW ENFORCEMENT PRACTICE OF USING COERCIVE MEASURES, SUCH AS ISOLATION AND INVOLUNTARY HOSPITALIZATION ON EPIDEMIOLOGICAL GROUNDS}

\begin{abstract}
The article examines the possibility of applying compulsory hospitalization and isolation to persons infected with the coronavirus, and to persons who have been in contact with the former. There are two mechanisms of coercion: coercive measures and mandatory measures. A distinction is made between the concepts of hospitalization and isolation, and legal subjects of the relevant legal relations are analyzed. The scientific and theoretical provisions of the article are illustrated by the author using the example of Russian legislation (codes and other federal laws, bylaws of the Ministry of Health of the Russian Federation and Rospotrebnadzor, relating to both substantive law and procedural law), as well as practice that has developed or is only emerging in domestic courts. At the end of the article, the existing regulatory problems, in particular conflicting regulation, are described and some solutions are proposed. Keywords: coronavirus, COVID-19, hospitalization, isolation, administrative coercion, administrative proceedings, measures of procedural coercion, code of administrative procedure of the Russian Federation, public health legislation.
\end{abstract}

2 а последние месяцы распространения новой коронавирусной инфекции COVID-19 (далее - коронавирусная инфекция) значительно увеличился объем административного регулирования в области санитарно-эпидемиологического благополучия населения. Одними из мер, широко применяемых на практике, являются обязательная изоляция и госпитализация. В данной связи встают вопросы о мере необходимого ограничения прав граждан в целом и эффективности механизма правоприменения в частности.

Различие принудительных и обязательных мер. До 2015 г. принудительная госпитализация осуществлялась в рамках гл. 35 ГПК РФ ${ }^{1}$ в медицинскую организацию, оказывающую психиатрическую помощь в стационарных условиях, в недобровольном порядке. Однако с 2015 г. данная глава была изъята из ГПК РФ и перенесена в новый Кодекс административного судопроизводства (КАС РФ)².

1 Гражданский процессуальный кодекс Российской Федерации от 14.11.2002 № 138-Ф3 (ред. от 06.04.2015) // СПС «КонсультантПлюс».

2 Кодекс административного судопроизводства Российской Федерации от 08.03.2015 № 21-Ф3 (ред. от 31.07.2020) // СПС «КонсультантПлюс». 


\begin{tabular}{|c|c|}
\hline 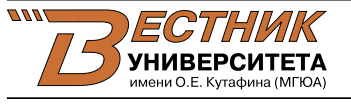 & $\begin{array}{l}\text { Соколова 口. В. } \\
\text { Проблемы регулирования и правоприменительная практика } \\
\text { применения мер принуждения в виде изоляции... }\end{array}$ \\
\hline
\end{tabular}

На фоне существования института госпитализации граждан в недобровольном порядке в психиатрический стационар (гл. 30 КАС РФ) также появился и институт госпитализации в противотуберкулезную организацию (гл. 31 КАС РФ). С учетом данного регулирования все чаще встает вопрос о принудительной госпитализации коронавирусных больных в судебном порядке. Более того, остается открытым вопрос о месте обязательных административных мер на основании п. 6 ч. 1 ст. 51 Федерального закона «О санитарно-эпидемиологическом благополучии населения» ${ }^{3}$.

Несмотря на различную практику судов первой инстанции по принудительной госпитализации коронавирусных больных ${ }^{4}$, для госпитализации в данном случае необходима законодательная база. Это подтверждается Обзором Президиума Верховного Суда РФ55. В вопросе 22 Президиум разъяснил, что «федеральный законодатель допускает медицинское вмешательство, а также принятие изоляционных мер различного характера в отношении соответствующих лиц в порядке, установленном законодательством». Следовательно, порядок медицинского вмешательства и изоляции должен быть установлен законодательством.

Согласно ст. 1 Федерального закона «О санитарно-эпидемиологическом благополучии населения» и п. 16 Перечня заболеваний, представляющих опасность для окружающих 6 , коронавирусная инфрекция является «инфекционным заболеваниям, представляющим опасность для окружающих». Поэтому п. 1 ст. 33 Федерального закона «О санитарно-эпидемиологическом благополучии населения» в качестве возможной меры предусматривает обязательную госпитализацию или изоляцию для определенных законом лиц. К таким лицам относятся: больные инфекционными заболеваниями, лица с подозрением на такие заболевания, контактировавшие с больными инфекционными заболеваниями, являющиеся носителями возбудителей инфекционных болезней (далее - лица, связанные с заболеванием).

Однако указанные обязательные меры по госпитализации и изоляции лиц, связанных с коронавирусной инфекцией, не тождественны принудительной госпитализации в психиатрический стационар или в туберкулезную организацию. Данное различие обосновывается следующими причинами.

3 Федеральный закон от 30.03.1999 № 52-Ф3 «О санитарно-эпидемиологическом благополучии населения» (ред. от 13.07.2020) // СПС «КонсультантПлюс».

4 См.: решение Горячеключевского городского суда Краснодарского края от 16.05.2020 по делу № 2a-739/2020 ; решение Яшалтинского районного суда Республики Калмыкия от 07.05.2020 по делу № 2а-67/2020 ; решение Брюховецкого районного суда Краснодарского края от 09.06.2020 по делу № 2a-583/2020 ; решение Облученского районного суда Еврейской автономной области от 20.05.2020 по делу № 2a-286/2020.

5 Обзор по отдельным вопросам судебной практики, связанным с применением законодательства и мер по противодействию распространению на территории Российской Федерации новой коронавирусной инфекции (COVID-19) № 1 (утв. Президиумом Верховного Суда РФ 21.04.2020) // СПС «КонсультантПлюс».

6 Перечень заболеваний, представляющих опасность для окружающих, утв. постановлением Правительства РФ от 01.12.2004 № 715 «Об утверждении перечня социально значимых заболеваний и перечня заболеваний, представляющих опасность для окружающих» // СПС «КонсультантПлюс». 
Во-первых, для обоих случаев принудительной госпитализации существуют специальный судебный порядок рассмотрения требований, который предусмотрен как в процессуальном законодательстве (гл. 30-31 КАС РФ), так и в материальных нормах (например, в ст. 29 и ст. 33 Закона РФ «О психиатрической помощи и гарантиях прав граждан при ее оказании» ${ }^{7}$, а также в ст. 10 Федерального закона «О предупреждении распространения туберкулеза в Российской Федерации» 8 ). Конечно, пп. 3 п. 1 ст. 274 КАС РФ указывает на возможность применения порядка, предусмотренного гл. 30 КАС РФ при рассмотрении иных требований о принудительной госпитализации, но только в том случае, если федеральным законом предусмотрен именно судебный порядок рассмотрения таких требований. Однако для принудительной госпитализации, связанной с инфекционным заболеванием, такой порядок законом не предусмотрен.

Во-вторых, процессуальные нормы для принудительной госпитализации также невозможно применить по аналогии с обязательными мерами, ссылаясь на п. 4 ст. 2 КАС РФ. Дело в том, что субъектный состав лиц, подлежащих принудительной госпитализации в туберкулезную организацию в соответствии с гл. 31 КАС РФ, существенно отличается от субъектного состава лиц, связанных с коронавирусной инфекцией. Так, согласно п. 2 ст. 10 Федерального закона «О предупреждении распространения туберкулеза в Российской Федерации», принудительная госпитализация применяется к больным заразными фрормами туберкулеза, неоднократно нарушающим санитарно-противоэпидемический режим, а также умышленно уклоняющимся от обследования в целях выявления туберкулеза или от лечения туберкулеза. Данный квалифицированный субъектный состав больных туберкулезом, установленный федеральным законом, существенно отличается от широкой группы лиц, подпадающих под действие санитарных норм по противодействию коронавирусной инфекции.

Таким образом, в связи с коронавирусной инфекцией невозможно применять к лицам меры принудительной госпитализации, а тем более изоляции.

В данном случае используется иной механизм принуждения, а именно обязательные меры. Для применения обязательных мер по госпитализации и изоляции, по смыслу п. 2 ст. 50, а также п. 6 ч. 1 ст. 51 Федерального закона «О санитарноэпидемиологическом благополучии населения», выносятся мотивированные предписания, которые обязательны к исполнению лицами в связи с коронавирусной инфекцией. Перечень основания вынесения таких предписаний является закрытым ${ }^{9}$. Нарушение предписания влечет наступление административной ответственности по ч. 2 ст. 6.3 КоАП РФ.

Таким образом, механизм принуждения, скорее, основывается на угрозе наступления административной ответственности в форме штрафа для физических лиц. При этом нельзя забывать и об уголовной ответственности, которая

7 Закон РФ от 02.07.1992 № 3185-1 «О психиатрической помощи и гарантиях прав граждан при ее оказании» (ред. от 19.07.2018) // СПС «КонсультантПлюс».

8 Федеральный закон от 18.06.2001 № 77-Ф3 «О предупреждении распространения туберкулеза в Российской Федерации» (в ред. от 03.08.2018 г.) // СПС «КонсультантПлюс».

9 Постановление Арбитражного суда Уральского округа от 05.02.2019 № \$09-194/19 по делу № A60-20552/2018. 


\begin{tabular}{|c|c|}
\hline 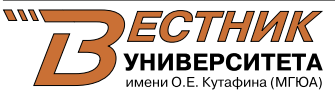 & $\begin{array}{l}\text { Соколова Ф. В. } \\
\text { Проблемы регулирования и правоприменительная практика } \\
\text { применения мер принуждения в виде изоляции... }\end{array}$ \\
\hline
\end{tabular}

наступает за нарушение санитарно-эпидемиологических правил, если оно повлекло по неосторожности массовое заражение (ч. 1 ст. 236 УК РФ) или смерть людей (ч. 2-3 ст. 236 УК РФ).

Различие изоляции и госпитализации. Несмотря на то, что обязательные госпитализация и изоляция в федеральном законодательстве чаще всего упоминаются вместе, между ними существует серьезное различие на уровне подзаконных актов. В данных вопросах полномочия по подзаконному нормотворчеству принадлежит Главному государственному санитарному врачу РФ и Федеральной службе по надзору в сфере защиты прав потребителей и благополучия человека (Роспотребнадзору) на основании п. 3 ст. 51 Закона «О санитарно-эпидемиологическом благополучии населения» и п. 1, 5.8.1, 8 Положения о Роспотребнадзоре ${ }^{10}$. В рамках данных полномочий Главный государственный санитарный врач РФ своими постановлениями утверждает санитарные правила, которые более подробно регулируют вопросы госпитализации и изоляции.

Санитарно-эпидемиологические правила СП 3.1.3597-2011 (далее - Правила) различают госпитализацию и изоляцию по категории лиц, к которым применяется та или иная обязательная мера. Так, согласно п. 5.1 Правил, госпитализации подлежат лица с подтвержденным диагнозом «коронавирусная инфекция», т.е. больные, или лица с подозрением на данное заболевание. Госпитализация данных лиц осуществляется не только по клиническим (например, с внебольничной пневмонией, п. 5.3 Правил), но и по эпидемиологическим показаниям: проживание в общежитии, отсутствие возможности самоизоляции при наличии в окружении указанных лиц, лиц, относящихся к группе риска.

В отличие от госпитализации, согласно п. 3.8 Правил, изоляции подлежат лица, контактировавшие с больными коронавирусной инфекцией. Они различаются по месту прохождения изоляции: в обсерваторе или по месту жительства. Согласно п. 4.3 Правил, этот вопрос разрешается в зависимости от эпидемических показаний, к которым относятся: наличие подозрений на коронавирусную инфекцию и отсутствие условий для изоляции в домашних условиях, как следует из п. 4.3.1 Методических рекомендаций Роспотребнадзора № 3.1.0170-2012.

Важно подчеркнуть, что к помещению в обсерватор допускаются только полностью здоровые контактировавшие люди, что подтверждается п. 1.3 Приложения к письму Роспотребнадзора от 22.03.2020 № 02/4708-2020-2713. Таким образом,

10 Постановление Правительства РФ от 30.06.2004 № 322 «Об утверждении Положения о Федеральной службе по надзору в сфере защиты прав потребителей и благополучия человека» // СПС «КонсультантПлюс».

11 Постановление Главного государственного санитарного врача РФ от 22.05.2020 № 15 «Об утверждении санитарно-эпидемиологических правил СП 3.1.3597-20 “Профилактика новой коронавирусной инфекции (COVID-19)"» (в ред. от 13.11.2020) // СПС «КонсультантПлюс».

12 Методические рекомендации Роспотребнадзора № MP 3.1.0170-20 (в редакции MP 3.1.0175-20 «Изменения № 1 в МР 3.1.0170-20 “Эпидемиология и профилактика COVID-19"», утвержденных Роспотребнадзором 30.04.2020).

13 Письмо Федеральной службы по надзору в сфере защиты прав потребителей и благополучия человека от 22.03.2020 № 02/4708-2020-27 «О направлении рекомендаций по

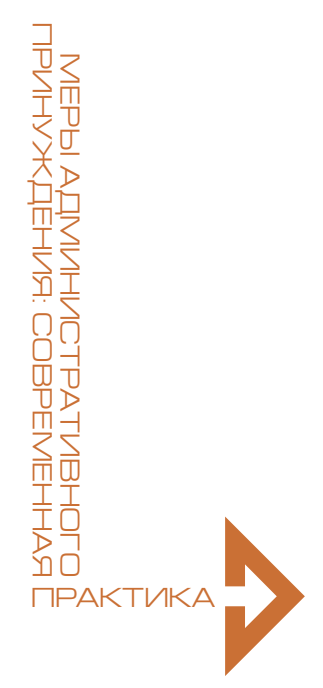


в актах Роспотребнадзора, эпидемиологические (эпидемические) показания для целей госпитализации и изоляции в обсерваторе различаются.

Однако Министерство здравоохранения РФ также участвует в нормотворчестве по данным вопросам, основывая свои полномочия по изданию нормативных актов в данной сфрере на Федеральном законе «Об основах охраны здоровья граждан в Российской Федерации» ${ }^{14}$ и п. 5.2.208 Положения о Министерстве здравоохранения $\mathrm{P}^{15}$. Акты Министерства также определяют субъектный состав лиц, подлежащих обязательной госпитализации. Как следует из п. 3 Приложения № 8 к приказу Министерства здравоохранения РФ от 19.03.2020 № 198н ${ }^{16}$, следующие лица подлежат госпитализации вне зависимости от тяжести заболевания: а) пациенты, относящиеся к группе риска;

б) пациенты, проживающие в общежитии, многонаселенной квартире, с лицами старше 65 лет, с лицами, страдающими хроническими заболеваниями бронхолегочной, сердечно-сосудистой и эндокринной систем.

Более того, в пп. «б» п. 3 данного Приложения указан дополнительный критерий, обязательный для оказания медицинской помощи на дому: у пациента должна иметься возможность находиться в отдельной комнате. Следовательно, пациенты, у которых нет такой возможности, также должны быть госпитализированы. В отсутствие наименования какой-либо группы лиц в такой классификации «эпидемиологической», параллели с регулированием Роспотребнадзора все же четко прослеживаются.

Акты Министерства также частично затрагивают прохождение изоляции в обсерваторе. Так, согласно п. 5.10 Временных методических рекомендаций № $9^{17}$, пациент с улучшающейся клинической картиной может быть выписан из стационара в обсерватор для целей изоляции до получения двух отрицательных ПЦРтестов в случае отсутствия у пациента условий для самоизоляции.

организации работы обсерватора для лиц, прибывших из регионов, неблагополучных по COVID-2019».

Согласно п. 1.1 данного Приложения, обсерватор - это специально приспосабливаемое учреждение для изоляции и медицинского наблюдения за лицами, прибывшими из эпидемически неблагополучной территории по новой коронавирусной инфекции. В настоящий момент, конечно, изоляцию в них проходят не только прибывшие из других регионов лица.

14 Федеральный закон от 21.11.2011 № 323-Ф3 «Об основах охраны здоровья граждан в Российской Федерации» (ред. от 29.11.2020) // СПС «КонсультантПлюс».

15 Постановление Правительства РФ от 19.06.2012 № 608 «Об утверждении Положения о Министерстве здравоохранения Российской Федерации» (ред. от 01.06.2020) // СПС «КонсультантПлюс».

16 Приказ Минздрава России от 19.03.2020 № 198н «О временном порядке организации работы медицинских организаций в целях реализации мер по профилактике и снижению рисков распространения новой коронавирусной инфекции COVID-19» (ред. от 30.10.2020) // СПС «КонсультантПлюс».

${ }_{17}$ Временные методические рекомендации «Профилактика, диагностика и лечение новой коронавирусной инфекции (COVID-19). Версия 9» (утв. Министерством здравоохранения РФ 26.10.2020). 


\begin{tabular}{|c|c|}
\hline 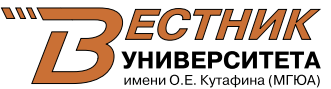 & $\begin{array}{l}\text { Соколова Ф. В. } \\
\text { Проблемы регулирования и правоприменительная практика } \\
\text { применения мер принуждения в виде изоляции... }\end{array}$ \\
\hline
\end{tabular}

Проблема дублирующего регулирования. Анализ субъектного состава лиц, подлежащих изоляции, по актам Роспотребнадзора и Министерства здравоохранения выявил определенные несоответствия. Интересно, что в п. 5.1 Методических рекомендаций Роспотребнадзора № 3.1.0170-20 присутствует разделение на госпитализацию по клиническим и эпидемиологическим показаниям, при том что клинические показания должны формироваться «с учетом критериев, установленных Минздравом России», а эпидемиологические остаются в компетенции Роспотребнадзора. Несмотря на это, акты двух органов исполнительной власти дублируют друг друга, что на практике приводит к путанице с опасными последствиями. Такими примерами являются: выписка больного «с улучшающейся клинической картиной» в обсерватор, где находятся здоровые контактные лица, что повышает риск заражения последних; госпитализация лица, которое хотя и живет в многонаселенной квартире, но имеет возможность самоизолироваться; изоляция контактного лица с подозрением на данное заболевание, которое должно быть госпитализировано; госпитализация больного, у которого отсутствует возможность самоизоляции из-за наличия в окружении других больных и т.д.

Устранить данные несоответствия возможно во взаимодействии Минздрава России и Роспотребнадзора в вопросе определения оснований для госпитализации и изоляции по каждому из критериев: клиническому и эпидемиологическому (эпидемическому). Это будет способствовать правовой определенности, уменьшению рисков распространения коронавирусной инфекции и снижению загруженности госпиталей и обсерваторов.

\section{БИБЛИОГРАФИЯ}

1. Жаворонкова Н. Г., Шпаковский Ю. Г. Правовые аспекты реформирования системы государственного управления защитой населения и территорий при чрезвычайных ситуациях: уроки пандемии COVID-19 // Вестник Университета имени О.Е. Кутафина (МГЮА). — 2020. — № 5 (69). — С. 130-142.

2. Пекшев А. В. Формирование единых межотраслевых подходов к надлежащему обеспечению биологической безопасности // Вестник Университета имени О.Е. Кутафина (МГЮА). — 2020. — № 5. — С. 74-82.

3. Тихомирова Ю. В. Некоторые вопросы возбуждения производства по административным делам о госпитализации гражданина в медицинскую организацию, оказывающую психиатрическую помощь в стационарных условиях, в недобровольном порядке; о продлении срока госпитализации в недобровольном порядке // Вестник Университета имени О.Е. Кутафина (МГЮА). — 2017. — № 3. - C. $80-87$. 